\title{
UM OLHAR DOS ESTUDANTES DO CURSO DE BIBLIOTECONOMIA ACERCA DO QUE SÃO DADOS, INFORMAÇÕES E CONHECIMENTOS
}

\section{A STUDENT'S LOOK AT THE DISCIPLINES OF THE BIBLIOTECONOMY COURSE ABOUT WHAT ARE DATA, INFORMATION AND KNOWLEDGE}

\author{
Cristiano Moreira \\ Joana Carlos Beirab \\ Marlene Oliveirac
}

\begin{abstract}
RESUMO
Introdução: Toda área do conhecimento possui seus termos e conceitos que são empregados para definir determinada ocorrência de um fato ou objeto específico. Devido à proximidade da Ciência da informação, Gestão do conhecimento e Biblioteconomia, alguns termos podem ter definições diferentes para descreverem 0 mesmo objeto. Objetivo: Sob essa ótica, buscou-se, no presente estudo, elucidar a seguinte inquietação: Quais as percepções dos discentes do curso de Biblioteconomia sobre o que é dado, informação e conhecimento? Metodologia: Para obter resposta a essa indagação, foi realizada uma pesquisa qualitativa, que se classifica como descritiva, em que se fez uso de um estudo bibliográfico acerca dos assuntos que norteiam essa temática, bem como da aplicação de um survey a discentes brasileiros e moçambicanos do curso de Biblioteconomia. Resultados: Foram obtidas 58 respostas válidas e, por meio das análises, foi possível verificar que não existe um consenso sobre as definições fornecidas, visto que os entrevistados acreditam que a inexistência de concordância pode vir a prejudicar o desenvolvimento profissional e acadêmico na área. Conclusão: Levando em consideração o quantitativo de respostas, se conclui que existe a necessidade de se realizar uma harmonização sobre alguns termos e conceitos adotados na C.I.
\end{abstract}

Descritores: Dado. Informação. Conhecimento. Biblioteconomia. Ciência da Informação.

\footnotetext{
a Doutorando no Programa de Pós-Graduação em Gestão \& Organização do Conhecimento da Universidade Federal de Minas Gerais (UFMG). E-mail: cristianomoreirasilva@hotmail.com.

b Doutorando no Programa de Pós-Graduação em Gestão \& Organização do Conhecimento da Universidade Federal de Minas Gerais (UFMG). E-mail: joanabeira@yahoo.com.br.

c Doutora pela Universidade de Brasília (UNB). Docente permanente no Programa de PósGraduação em Gestão \& Organização do Conhecimento da Universidade Federal de Minas Gerais (UFMG). E-mail: marleneotmelo@gmail.com.
} 


\section{INTRODUÇÃO}

A sociedade contemporânea está acompanhando o avanço da Ciência e da Tecnologia em todos os seus segmentos. Com a evolução de novos dispositivos tecnológicos e a ampliação da utilização das Tecnologias da Informação e Comunicação (TICs) tanto no campo científico, quanto no campo profissional, causou impacto em algumas áreas científicas como Medicina, Biologia etc.

Nesse sentido, o campo da Ciência e de cada um de suas áreas é delineada pelos problemas que the são apresentados. No caso da Ciência da Informação $(\mathrm{Cl})$, é considerada uma disciplina científica, pois atua tanto na pesquisa científica (focada em teorias, quanto na aplicação profissional,) movida pela necessidade de resolver problemas na construção de Bibliotecas digitais, Bases de dados, Repositórios institucionais etc.

A Ciência da Informação não conta ainda com pleno consenso de suas teorias e conceitos fundamentais. Há assim, divergências entre grupos de pesquisadores e de grupos de profissionais. A última pesquisa realizada para averiguar as teorias e conceitos usados pelos pesquisadores foi realizada por C. Zins que reuniu 57 pesquisadores de 16 países e usou a técnica crítica Delphi. Sua pesquisa foi publicada em quatro artigos. O capítulo em que pergunta sobre o conceito de Ciência da Informação, resultou ao final em 50 conceitos diferentes. Outro artigo, que trata de dado, informação e conhecimento resultou em 130 definições diferentes entre os pesquisadores consultados.

Frente a esse contexto, observa-se que a Ciência da Informação desenvolve pesquisas as vezes em constructos distintos, mas, mesmo assim tenta consolidar seu campo científico. A área se orienta por diferentes abordagens e tradições, o que implica em fragmentação do conhecimento. Conforme Zins (2007a) destaca, os conceitos sobre dado, informação e conhecimento estão diretamente interligados na Ciência da Informação.

As reflexões presentes nos estudos de Zins (2007a; 2007b) motivaram a realização da presente pesquisa, uma vez que, nesses estudos, é explicitada a 
percepção de importantes pesquisadores da área quanto ao entendimento dos conceitos de dado, informação e conhecimento. No entanto, notou-se a falta dessa compreensão por parte de outros perfis como os dos estudantes da Ciência da Informação, o que levou este estudo a buscar responder tal indagação: Quais as percepções dos discentes do curso de Biblioteconomia sobre o que são: dado, informação e conhecimento?

A realização desse estudo se justifica na intenção de buscar dentre os estudantes brasileiros e moçambicanos conceitos de dado, informação e conhecimento e, também da Ciência da Informação.

Para responder a essa questão, foram entrevistados discentes do curso de Biblioteconomia, Ciência da Informação e jornalismo, em instituições do Brasil e de Moçambique. A escolha desse perfil foi, inicialmente, motivada pela acessibilidade e maior facilidade de contato com tais cursos. Mas foi importante o fato de investigar essa temática em estudantes de graduação que estão em formação em Biblioteconomia e Ciência da Informação.

O objetivo foi levantar e analisar noções de dado, informação e conhecimento apreendidos por estudantes de graduação e biblioteconomia e Ciência da Informação do Brasil e de Moçambique.

\section{REFERENCIAL TEÓRICO}

Neste tópico, serão discutidas as principais teorias da literatura específica que trata das definições do que são: dado, informação e conhecimento e os principais estudos encontrados e em sinergia com o objeto de estudo desta pesquisa.

\subsection{Compreensão dos Conceitos de Dado, INFORMAÇÃo E ConHeCimento}

Os conceitos de dado, informação e conhecimento são tidos como elementos essenciais para a comunicação e para a tomada de decisão dentro de qualquer organização. No entanto, tais conceitos nos dias atuais ainda são pouco evidentes e de difícil delimitação. Assim, há necessidade que sejam feitas mais pesquisas com o objetivo de compreender o significado de cada um 
deles. (ANGELONI, 2003). De acordo com esta autora, o que é entendido como dado por um indivíduo ou usuário de informação pode ser informação e/ou conhecimento para outro. Não obstante, Davenport e Prusak (1998a), afirmam que, durante anos, as pessoas se referiram a dados como informação; agora, percebem que falar de conhecimento pode ser o mesmo que falar sobre a informação - daí a popularidade da gestão do conhecimento.

Para Zins (2007a), os dados são comumente concebidos como a matéria-prima para a informação, que é concebida como matéria-prima para o conhecimento. Assim, o conhecimento pode ser compreendido como a construção de maior ordem. Na ótica do autor, os cientistas da informação são obrigados a fazer uma revisão periódica e, sempre que for necessário, redefinir seus blocos de construções teóricas fundamentais, devido às constantes dinâmicas do próprio campo da ciência de informação.

Desse modo, construir uma sociedade em que todos possam criar, acessar, utilizar e compartilhar informação e conhecimento é o desafio que se impõe a todas as nações e corporações no mundo atual, intensamente baseado em tecnologias da informação e do conhecimento, no qual os ativos intangíveis adquirem importância crescente. (TAPARANOFF, 2006). Entendese, portanto, que os termos dados, informação e conhecimento são distintos, mas estreitamente relacionados, sendo importante ter uma ideia clara do que eles são exatamente, o que permite abrir espaço para que cada conceito seja analisado de maneira isolada.

\subsubsection{Dados}

Segundo Davenport e Prusak (1998a), dados são observações sobre o estado do mundo. São, de igual maneira, considerados como um conjunto de fatos em estado bruto a partir dos quais podem ser tiradas conclusões. A título de exemplo, podem ser considerados dados objetos como: cartas escritas à mão, livros impressos, fotos de família, filmes em fita de vídeo, cópias assinadas de papéis de hipotecas, livro-razão de um banco e cadernetas bancárias do titular de uma conta, entre outras. (SOMASUNDARAM: 
SHRIVASTAVA, 2011).

Setzer (1999), define dado como uma sequência de símbolos quantificados ou quantificáveis, sendo que, se um texto é um dado, e as letras são símbolos quantificados, o alfabeto por si só se constitui numa base numérica. Para o autor, também são dados as imagens, sons e animação. Uma vez que todos podem ser quantificados a ponto de alguém que entra em contato com eles ter eventualmente dificuldade de distinguir a sua reprodução, a partir da representação quantificada, com o original. $O$ autor sublinha a importância de perceber que qualquer texto constitui um dado ou uma sequência de dados, mesmo que ele seja ininteligível para o leitor. Corroborando, dados são elementos brutos, sem significado, desvinculados da realidade que constituem a matéria-prima da informação. (ANGELONI, 2003).

Ademais, de acordo com a sua natureza, os dados podem ser classificados como estruturados ou não estruturados. Dados estruturados são organizados em linhas e colunas em um formato definido de forma rígida, de modo que os aplicativos possam recuperá-los e processá-los com eficiência. Por sua vez os dados não estruturados referem-se a todos os dados cujos elementos não podem ser armazenados como linhas e colunas, sendo difíceis de consultar e recuperar através de aplicativos empresariais, (SOMASUNDARAM; SHRIVASTA, 2011). Para Setzer (1999), a definição de dado é necessariamente uma entidade matemática e, dessa forma, puramente sintática, podendo ser completamente descrito por meio de representações formais e estruturais.

\subsubsection{Informação}

A informação tornou-se um recurso deveras importante na contemporaneidade. Com a globalização, vive-se em um mundo de constantes dependências e procura da informação a todo o momento.

Nessa perspectiva, a informação torna-se um fator determinante para a melhoria de processos, produtos e serviços, tendo valor estratégico em organizações. A ideia da informação como ferramenta estratégica desenvolveu- 
se depois que a gestão da informação modificou o foco inicial de gestão de documentos e dados para a ideia de recursos informacionais, mostrando resultados em relação à eficiência operacional, evitando-se o desperdício e automatizando os processos. (TAPARANOFF, 2006).

Numa visão generalista, informação é tida como a inteligência e o conhecimento derivados dos dados. Abrange, nesse caso, as três dimensões: dado, informação e conhecimento; e serve de conexão entre os dados brutos e o conhecimento que se pode eventualmente obter. (SOMASUNDARAM; SHRIVASTA, 2011).

A informação, de acordo com Drucker apud Davenport e Prusak (1998a) e Angeloni (2003), é definida como dados com significados, dotados de relevância e propósito.

A informação, por outro lado, toma a forma de dados estruturados e formatados que permanecem passivos e inertes até serem usados por aqueles com o conhecimento necessário para interpretá-los e processá-los. (DAVID; FORAY, 2003).

Assim, o simples gesto de acessar a Internet para fazer consultas, participar de redes sociais, enviar e receber mensagens (e-mail), compartilhar mensagens quer sejam vídeos, quer sejam imagens, entre outros, fazem da informação mais valiosa ao ser compartilhada com e por outras pessoas.

Não obstante, com o passar do tempo, o valor da informação sofre mudanças, tornando-a menos valiosa quando usada e acessada com menos frequência e menos regularidade. Corroborando com tal raciocínio, Taparanoff (2006) ressalta que as informações devem ser usadas de modo que possam criar significados, construir conhecimentos e auxiliar na tomada de decisões. Consequentemente, a criação do conhecimento representa inovação e vantagem competitiva.

\subsubsection{Conhecimento}

Em momento de globalização e do aumento da concorrência em todo o mundo, muitas organizações estão procurando novas maneiras de ganhar 
vantagem competitiva. Ao fazer isso, tais organizações estão tentando usar uma variedade de recursos organizacionais. Hoje, o conhecimento, como um ativo intangível, tornou-se favorito sobre os recursos organizacionais tradicionais como o capital e o trabalho. (HUSAIN; NAZIM, 2013).

O conhecimento tem estado no coração do crescimento econômico e do aumento gradual dos níveis de bem-estar social desde tempos imemoriais. (DAVID; FORAY, 2003). Tornou-se extremamente relevante para as organizações desde a mudança da economia Industrial, baseada em linhas de montagem e controles hierárquicos, para uma economia global, descentralizada e baseada na informação.

$\mathrm{Na}$ economia da informação, o conhecimento se torna o mais importante fator de produção, sendo fundamental na forma de gerenciar este novo recurso empresarial. (BORGHOFF; PAREARESCHI, 1998; RODRIGUES; MACCARI, 2014).

Para Sveiby (1998), com bases em Polanyi (1967) e Wittgenstein (1962), o conhecimento é definido como a capacidade de agir, sendo elemento extremamente valioso, por se aproximar e/ou levar a uma acção. Nesse sentido, tem-se três importantes aspectos:

1. O conhecimento presume-se em crenças $e$ compromissos;

2. Relaciona-se a uma ação e;

3. Quando intimamente articulado ao contexto, a informação e o conhecimento transmitem um significado. E a sua gestão incide na atividade de divulgar e explicitar os saberes implícitos nas práticas individuais e colectivas das organizações. (NONAKA; TAKEUCHI, 1997, p. 66).

De acordo com Davenport e Prusak (1998a), toda a informação valiosa e de difícil gerenciamento denomina-se conhecimento. É valiosa precisamente porque alguém deu à informação um contexto, um significado, uma interpretação. Refletiu sobre o conhecimento, acrescentou a ele sua própria sabedoria e considerou suas implicações mais amplas. Para o autor, conhecimento não é dado e também não se traduz em informação. Segundo o autor, conhecimento tem uma vantagem competitiva e sustentável. Forma uma mistura fluida de experiência condensada, valores, informação contextual e 
insight experimentado o que proporciona uma estrutura para a avaliação e a incorporação de novas experiências e informações. (DAVENPORT; PRUSAK, 1998b, p 6).

Conforme Husain e Nazim (2013), o conhecimento também pode ser definido como uma crença pessoal justificada, que aumenta a capacidade de 0 indivíduo tomar medidas eficazes, as quais, dentro de uma organização, são distintas quer da forma expressa, quer da forma tácita. O conhecimento explícito é tido como formal e sistemático, que pode ser expresso em palavras ou números, os quais podem ser documentados ou armazenados em bancos de dados como, por exemplo, registros eletrônicos. Em ambas as formas, esse conhecimento pode ser compartilhado entre os indivíduos por meio de discussão, de histórias e de interações pessoais. O conhecimento explícito inclui, ainda, habilidades, experiências, perspicácias, intuição e julgamento. (HUSAIN; NAZIM, 2013).

O conhecimento, em qualquer campo, propicia a seus possuidores a capacidade de ação intelectual ou física. Então, o que queremos dizer com conhecimento é fundamentalmente uma questão de capacidade cognitiva. (DAVID; FORAY, 2003).

\subsubsection{Tipos de conhecimento}

$\mathrm{Na}$ gestão do conhecimento e nas organizações, conforme Rodrigues e Maccari (2003), distingue-se a existência de dois tipos de conhecimento: o explícito e o tácito. O conhecimento explícito pode ser transmitido de forma relativamente fácil, de maneira sistemática entre os indivíduos de uma organização. Para estes autores, o conhecimento formal da organização pode ser encontrado nas formalizações que ela tem sobre si mesma, tais como organogramas, fluxos internos, estatutos e missão, áreas de atuação, patentes, documentos, entre outras. Também representa o conhecimento que tradicionalmente tem sido manipulado por meio da tecnologia de Informação e pode ser encontrado nos documentos de qualquer organização, como relatórios, artigos, manuais, bancos de dados, vídeos, entre outros. 
O conhecimento tácito é considerado o mais importante, porque se refere ao conhecimento pessoal adicionado à experiência individual. Este conhecimento possui uma importante dimensão cognitiva, por envolver fatores intangíveis, como crenças valores, perspectiva, sistemas de valor baseado em experiências individuais. (RODRIGUES; MACCARI, 2003).

Para Nonaka e Takeuchi (1997), o conhecimento explícito é aquele transmissível por meio da linguagem sistemática e formal. Para esses autores, o conhecimento só existe, reside e é criado por indivíduos, e sua construção acontece apenas quando introduzido em uma dada coletividade. Consequentemente, uma organização não pode criar conhecimento sem indivíduos.

Além de corroborar com as características mencionadas, Choo (1996) traz ao conceito de conhecimento uma terceira dimensão, a saber, o conhecimento cultural, que consiste em estruturas cognitivas e afetivas que são habitualmente utilizadas pelos membros da organização com 0 intuito de perceber, explicar, avaliar e construir a realidade. Sveiby (1998), por sua vez, Polanyi (1967), destaca quatro características de conhecimento, a saber:

1. Conhecimento tácito;

2. Conhecimento orientado para ação;

3. Conhecimento sustentado por regras e ;

4. Conhecimento em constante mutação.

Em complemento, Tarapanoff (2006) afirma que novos conhecimentos podem ser criados por meio da conversão do conhecimento, pela construção do conhecimento e pela conexão do conhecimento. Ao citar Nonaka e Takeuchi (1995), destaca que, na conversão do conhecimento, busca-se transmudar o conhecimento tácito de indivíduos criativos em conhecimento explícito. Segundo os autores conceitos criados são avaliados, testados e elaborados por meio de arquétipos e protótipos, segundo sua adequação aos propósitos da organização e, posteriormente, transferidos para outros níveis da empresa Esse movimento é realizado para desencadear novos ciclos de criação de conhecimento. (NONAKA; TAKEUCHI, 1995) apud (TARAPANOFF, 2006). 


\subsection{O CuRso de Biblioteconomia e sua RelaÇÃo Com a CiênCIa da InformaÇão E GESTÃO dO CONHECIMENTO}

Etimologicamente, o termo ciência provém da palavra em latim scientīa, $a e$ ' que significa conhecimento, saber, ciência, arte, habilidade. Essa definição etimológica, entretanto, não é suficiente para diferenciar a ciência de outras atividades também envolvidas com o aprendizado e com o conhecimento, (PRODANOV; FREITAS, 2013). Entender o contexto que contribuiu para o surgimento da Biblioteconomia e da Ciência da Informação é uma premissa necessária para atribuir a cada qual a sua função, mesmo que em determinados momentos ambas atuem juntas em prol da resolução de problemas.

Desde seu surgimento, a Biblioteconomia se apresentava estritamente vinculada às bibliotecas, o que pode estar diretamente relacionado à sua denominação. No entanto, com a inserção de novas tecnologias e com a sociedade da informação e do conhecimento, surgiram outras oportunidades de atuação profissional para essa área.

Não é algo fácil delinear o nascimento de uma nova ciência, mesmo sendo uma ciência relativamente nova, bem como o surgimento de esforços para enfrentar os problemas da organização, crescimento e disseminação do conhecimento registrado, oriundos de novas demandas da sociedade, (OLIVEIRA, 2011). Essas necessidades se intensificaram após a Segunda Guerra Mundial, ou seja, o surgimento da Ciência da Informação é atribuído ao contexto da revolução cientifica e técnica que se seguiu a esse período, (SARACEVIC, 1996).

Para alguns pesquisadores, a origem da Ciência da Informação sofreu fortes influências de duas áreas específicas do conhecimento, as quais contribuíram com o seu surgimento e desenvolvimento, a saber, a Documentação, que introduziu conceituações novas, e a Recuperação da Informação, que possibilitou o surgimento de novos artefatos, como softwares que contribuíram para a eficiente recuperação da informação. (OLIVEIRA, 2011).

O conhecimento na Biblioteconomia está diretamente vinculado ao conhecimento explícito gerado dentro das organizações e ambientes de 
pesquisas como, por exemplo, relatórios, diretrizes, memorandos, atas de reunião, artigos de periódicos, livros, teses etc., ou adquiridas a partir de formas externas, incluindo periódicos bancos de dados, relatórios externos, informações do governo, etc. (HUSAIN; NAZIM, 2013).

A Ciência da Informação não é uma ciência derivada da Biblioteconomia, conforme é sugerido por alguns pesquisadores, pois cada uma delas se sustenta em crenças e paradigmas distintos. As teorias da Ciência da Informação, conforme Oliveira (2011), origina-se de teorias de campos variados como: Linguística, Ciência da Computação, Administração, Comunicação social, Psicologia, Biblioteconomia, Lógica, Matemática, Filosofial Epistemologia. Com o auxílio das novas tecnologias de informação a Ciência da Informação e Biblioteconomia tem feito uma parceria para garantir novas práticas vinculados aos serviços bibliotecários. Ainda segundo a autora as duas áreas atuam juntas na busca de resoluções do mesmo problema que é organizar e disponibilizar e tornar acessível documentos em todas as áreas do conhecimento, contudo, cada uma representa um campo do conhecimento norteado por paradigmas diferentes. (OLIVEIRA, 2011).

A função da biblioteca em uma sociedade da informação depende do tipo da Instituição a que se dedica para entender as suas funções, as bibliotecas atendem a Sociedade como um todo por meio dos seus variados tipos de bibliotecas; escolares, universitárias, especializadas etc. A função básica de uma biblioteca é a organização, preservação dos registros da informação tornando-os acessíveis. A organização da informação, envolve importantes técnicas de catalogação, classificação e indexação. A biblioteca tem a função de disseminar a informação por meio da criação e oferta de inúmeros serviços de disseminação. (OLIVEIRA, 2011).

Outro construto importante é a Gestão do conhecimento que Cajueiro, Sicsu e Ribeiro (2009) a definem como:

Uma forma sistemática de perceber os conhecimentos existentes na organização e como aproveitar o potencial em seu benefício, considerando o conhecimento existente internamente, sua transferência para os demais membros, assim como a criação de novos conhecimentos. (CAJUEIRO; SICSU; RIBEIRO, 2009, p. 223) 
A Gestão do conhecimento é implementada em organizações e estudadas pela Ciência da Informação, Administração, Educação etc.

Os temas explorados pela Biblioteconomia, Ciência da Informação e Gestão do conhecimento passam a impressão de que estão interligados e interdependentes, pelo fato dessas áreas trabalharem com a informação e com o conhecimento, mantendo-se em um processo que transforma dado em informação, informação em conhecimento, conhecimento em sabedoria, em um ciclo contínuo.

\subsection{Estudos CorRELATOS}

Em seu estudo Aharony (2006) analisou as percepções de 118 estudantes de ciência da informação de graduação matriculados em três programas diferentes de Ensino Superior em Israel. De acordo com o autor os papéis clássicos tradicionalmente desempenhados nas bibliotecas ainda eram percebidos como tarefas do bibliotecário.

As tarefas relacionadas com a própria informação, tais como recuperação de informação (construção, operação e gerenciamento de sites), informações de filtragem, combinando informações de perfil pessoal do cliente eram atribuídas ao cientista da informação.

Nos três programas diferentes, os alunos perceberam a imagem do profissional cientista da informação em posição hierárquica mais alta que a do bibliotecário. Se os alunos têm uma perspectiva ampla e positiva da profissão, então talvez haja uma necessidade de enfatizar os tópicos técnicos relacionados com o papel do cientista da informação.

Em seu estudo, Zins (2007a) apresenta um quadro que registra os resultados obtidos por meio da aplicação do Painel Delphi, que buscou apresentar as inúmeras definições possíveis entre dado, informação e conhecimento, na perspectiva de 57 especialistas em Ciência da Informação oriundos de 16 países. Entre as principais definições, foram escolhidas quatro para ilustrar as inúmeras possibilidades de definição para os termos em questão, conforme quadro 1 a seguir: 


\section{Quadro 1 - Definições de Dados, Informação e Conhecimento}

\begin{tabular}{|c|c|c|c|}
\hline Respondente & Dado & Informação & Conhecimento \\
\hline $\begin{array}{l}\text { Donald } \\
\text { Hawkins }\end{array}$ & $\begin{array}{l}\text { Dados são fatos e } \\
\text { estatísticas que podem } \\
\text { ser quantificados, } \\
\text { medidos, contados e } \\
\text { armazenados. }\end{array}$ & $\begin{array}{l}\text { Informação são dados } \\
\text { que são categorizados, } \\
\text { contados e, assim, o } \\
\text { dado adquire } \\
\text { significado, relevância } \\
\text { ou propósito. }\end{array}$ & $\begin{array}{l}\text { Conhecimento emerge } \\
\text { da análise, reflexão e } \\
\text { síntese da informação. É } \\
\text { usado para fazer a } \\
\text { diferença em uma } \\
\text { empresa, aprenda uma } \\
\text { lição ou resolva um } \\
\text { problema. }\end{array}$ \\
\hline $\begin{array}{l}\text { Quentin L. } \\
\text { Burrell }\end{array}$ & $\begin{array}{l}\text { São os itens individuais } \\
\text { básicos de informação } \\
\text { numérica ou outra, } \\
\text { acumulou através da } \\
\text { observação; mas em si } \\
\text { mesmos, sem contexto, } \\
\text { eles são desprovidos de } \\
\text { informações. }\end{array}$ & $\begin{array}{l}\text { É aquela que é } \\
\text { transportada, } \\
\text { possivelmente, } \\
\text { acessível à análise e } \\
\text { interpretação, por meio } \\
\text { de dados e o contexto } \\
\text { no qual os dados são } \\
\text { montados. }\end{array}$ & $\begin{array}{l}\text { O entendimento geral e } \\
\text { consciência obtida a } \\
\text { partir de informação } \\
\text { acumulada, temperada } \\
\text { pela } \\
\text { permitindo que noviência, } \\
\text { contextos novos } \\
\text { previstos }\end{array}$ \\
\hline $\begin{array}{l}\text { William } \\
\text { Hersh }\end{array}$ & $\begin{array}{lr}\text { Dados são } & \text { fatos } \\
\text { atômicos, elementos } \\
\text { básicos da } & \text { "verdade", } \\
\text { sem interpretação. Os } \\
\text { dados sar as } \\
\text { observações brutas } \\
\text { sobre o mundo } \\
\text { coletadas por cientistas } \\
\text { e outros, com um } \\
\text { mínimo de interpretação } \\
\text { contextual. }\end{array}$ & $\begin{array}{l}\text { Informação de é a } \\
\text { agregação de dados } \\
\text { para tornar as } \\
\text { observações coerentes } \\
\text { sobre o mundo. }\end{array}$ & $\begin{array}{l}\text { Conhecimento são as } \\
\text { regras e os princípios } \\
\text { organizadores reunidos } \\
\text { nos dados para agregá- } \\
\text { los às informações }\end{array}$ \\
\hline Donald Kraft & $\begin{array}{l}\text { Dados são fatos } \\
\text { atômicos, elementos } \\
\text { básicos da "verdade", } \\
\text { sem interpretação ou } \\
\text { maior contexto. Está } \\
\text { relacionado a coisas } \\
\text { que não tem sentido. }\end{array}$ & $\begin{array}{l}\text { É um conjunto de dados } \\
\text { com a capacidade de } \\
\text { processamento } \\
\text { adicional, tal como } \\
\text { contexto, as relações } \\
\text { para outros fatos sobre } \\
\text { as mesmas ou } \\
\text { relacionadas objetos, o } \\
\text { que implica uma maior } \\
\text { utilidade. Informação } \\
\text { fornece significado aos } \\
\text { dados }\end{array}$ & $\begin{array}{l}\text { É uma informação com } \\
\text { mais contexto e e } \\
\text { compreensão, talvez } \\
\text { com a adição de regras } \\
\text { para estender as } \\
\text { definições e permitir } \\
\text { inferência. }\end{array}$ \\
\hline
\end{tabular}

Fonte: Elaborado pelos autores com base em Zins (2007a)

O estudo de Husain e Nazim (2013) teve como objetivo identificar, recolher e rever criticamente a literatura de pesquisa sobre os conceitos de Gestão do Conhecimento aplicados aos profissionais da Biblioteconomia e da Ciência da Informação. Para isso usou a revisão de trabalhos publicados em ambos os campos. Chegaram a algumas evidências como o conhecimento que está incorporado em pessoas (sua habilidade e experiência) e o conhecimento 
dos processos de trabalho das bibliotecas (conhecimento explícito) são reconhecidos como importantes fontes de conhecimento dentro de bibliotecas. Nesse sentido, as competências dos profissionais da Biblioteconomia e Gestão da Informação podem ser muito benéficas para a gestão do conhecimento, visto que há uma necessidade de adquirir competências adicionais nas áreas de comunicação, gestão de recursos humanos, gestão de mudanças, gestão de projetos.

\section{PROCEDIMENTOS METODOLÓGICOS}

Trata-se de uma pesquisa descritiva com abordagem qualitativa. Os procedimentos aplicados para a realização foram os bibliográficos, que, segundo (Raupp; Beuren, 2006), são parte obrigatória, pois é com esse instrumento que se apresenta a produção científica existente relacionada ao objeto de estudo.

Para a mostra da pesquisa foram selecionadas três instituições no Brasil e duas em Moçambique:

- Curso de Biblioteconomia à distância da Escola Universo - unidade de Belo Horizonte.

- Curso de Biblioteconomia da Universidade Federal de Minas Gerais, aplicados em alunos de $7^{\circ}$ e $8^{\circ}$ períodos.

- Curso de Biblioteconomia a distância do Claretiano- polo de Belo Horizonte.

- Curso de Ciência da Informação da Universidade Eduardo Mondlane em Moçambique.

- Escola Superior de Jornalismo de Moçambique.

\subsection{Procedimentos de Coleta dos dados}

O procedimento adotado foi a adoção de um questionário. Os autores Prodanov e Freitas (2013) declaram que, em geral, a coleta é realizada em um grupo representativo de respondentes acerca do problema apontado na pesquisa e, posteriormente, são realizadas as análises para se construir as 
evidências necessárias sobre o objeto de estudo.

Desse modo, elaborou-se um questionário que, posteriormente, foi submetido a pré-teste com o intuito de se verificar se existia alguma falha, inconsistência, ambiguidades, sendo adotadas as correções apontadas.

O contato para a distribuição do questionário foi feito com coordenadores dos cursos. Assim, foram distribuídos via internet para alunos das seguintes instituições: Os coordenadores então enviaram para as turmas com mais potencial para responde-los. Foram enviados um total de 180 questionários. A mostra chegou a $32 \%$ do total enviado

\subsection{Procedimentos de análise dos dados}

$\mathrm{Na}$ análise dos dados seguiu-se os mesmos procedimentos de Zins (2007a). Contudo retirou-se as respostas iguais elou mal formuladas.

\section{RESULTADOS E DISCUSSÃO}

\subsection{Perfil da mostra}

Os questionários aplicados em discentes dos cursos de Biblioteconomia de instituições de Ensino Superior do Brasil e de Moçambique, mostrou um retorno 58 respostas válidas, sendo 42 retornos de brasileiros e 16 de moçambicanos ${ }^{1}$. Na figura 1 a seguir:

Figura 1 - Caracterização da amostra (primeira parte)

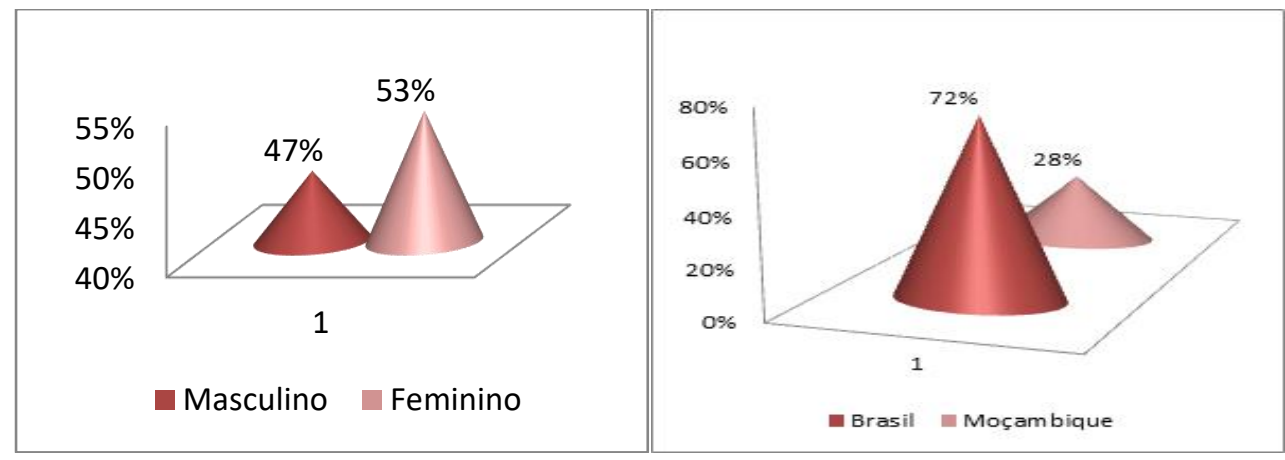

Fonte: Resultados da pesquisa (2018)

\footnotetext{
${ }^{1}$ A escolha do perfil desses estudantes foi feita pelos coordenadores dos cursos.
} 
Observa-se que 53\% dos respondentes são do gênero feminino e que a maioria dos representantes é de nacionalidade brasileira.

\subsection{ENTENDIMENTOS DE INFORMAÇÃO E CONHECIMENTO NA VISÃO dOS GRADUANDOS}

Apresenta-se aqui algumas respostas dos participantes acerca do entendimento que absorveram dos termos: dado, informação e conhecimento. Tais respostas foram organizadas no Quadro 2 a seguir:

\section{Quadro 2 - Entendimentos de dado, informação e conhecimento na visão dos graduandos}

\begin{tabular}{|c|c|c|c|}
\hline Respondente & Dado & Informação & Conhecimento \\
\hline 1- Moçambique & $\begin{array}{l}\text { Dados são } \\
\text { informações, } \\
\text { elementos, materiais, } \\
\text { bases, fatos, valores } \\
\text { ou ocorrências pelas } \\
\text { quais são obtidas } \\
\text { informações com o } \\
\text { objetivo de adquirir } \\
\text { benefícios } \\
\text { determinado ou } \\
\text { conhecimento. }\end{array}$ & $\begin{array}{lr}\text { Informações } & \text { são } \\
\text { dados, processados } \\
\text { ou não, que podem } \\
\text { ser utilizados para } \\
\text { produção } & \text { e } \\
\text { transmissão } & \text { de } \\
\text { conhecimento, } \\
\text { registrados } \\
\text { qualquer suporte ou } \\
\text { formato. }\end{array}$ & $\begin{array}{l}\text { Conhecimento é o } \\
\text { resultado de um } \\
\text { processamento complexo } \\
\text { e subjetivo da informação, } \\
\text { conjunto de informações } \\
\text { que o indivíduo adquire por } \\
\text { meio da sua experiência, } \\
\text { aprendizado, crenças, } \\
\text { valores etc. }\end{array}$ \\
\hline 3- Moçambique & $\begin{array}{l}\text { Conjunto } \\
\text { símbolos } \\
\text { envolve informação }\end{array}$ & $\begin{array}{lr}\text { São } & \text { dados } \\
\text { agrupados } & \text { que } \\
\text { geram sentido } & \end{array}$ & $\begin{array}{l}\text { Resultado de várias } \\
\text { informações organizadas } \\
\text { de forma lógica e suficiente } \\
\text { para criar um evento }\end{array}$ \\
\hline 5 - Moçambique & $\begin{array}{lr}\text { São itens } & \text { que } \\
\text { trabalhados } \\
\text { equivalem } \\
\text { informação. }\end{array}$ & $\begin{array}{l}\text { Trata-se do conjunto } \\
\text { de dados já } \\
\text { trabalhados. }\end{array}$ & $\begin{array}{l}\text { Entendo como se fosse } \\
\text { informação que foi } \\
\text { apropriada pelo individuo } \\
\text { desde que seja utilitária. }\end{array}$ \\
\hline 6 - Moçambique & $\begin{array}{l}\text { Dados são códigos } \\
\text { ou informações não } \\
\text { analisadas que } \\
\text { facilitam a fabricação } \\
\text { de conhecimento. }\end{array}$ & $\begin{array}{lr}\text { Informação é um } \\
\text { conjunto de dados } \\
\text { organizados que } \\
\text { constitui uma } \\
\text { mensagem sobre um } \\
\text { determinado } \\
\text { fenômeno ou evento. }\end{array}$ & $\begin{array}{l}\text { Conhecimento é uma } \\
\text { diversidade de } \\
\text { informações adquiridas por } \\
\text { indivíduo ao longo da vida } \\
\text { por meio de aprendizagem, } \\
\text { crenças religiosas, } \\
\text { culturais, profissionais, } \\
\text { sociais nas relações } \\
\text { interpessoais do dia a dia. }\end{array}$ \\
\hline 8 - Moçambique & $\begin{array}{lr}\text { Dado refere-se a um } \\
\text { conjunto } & \text { de } \\
\text { informação } & \\
\text { organizada } & \text { que } \\
\text { permite chegar } & \text { ao } \\
\text { conhecimento } & \text { de } \\
\text { algo ou deduzir as } \\
\text { consequências de } \\
\text { um facto. }\end{array}$ & $\begin{array}{lr}\text { Entendo informação } \\
\text { como sendo o } \\
\text { conjunto organizado } \\
\text { de dados que } \\
\text { constitui } r \text { uma } \\
\text { mensagem e tem } \\
\text { comor objetivo } \\
\text { aprofundar r o } \\
\text { conhecimento sobre } \\
\text { um determinado }\end{array}$ & $\begin{array}{l}\text { Conhecimento é o conjunto } \\
\text { de informações que o } \\
\text { indivíduo adquire por meio } \\
\text { da sua experiência, } \\
\text { aprendizagem e crenças } \\
\text { que pode mudar o } \\
\text { comportamento e auxiliar } \\
\text { na tomada de decisão, e } \\
\text { pode ser transmitido de } \\
\text { geracão em geracão. }\end{array}$ \\
\hline
\end{tabular}




\begin{tabular}{|c|c|c|c|}
\hline & & assunto. & \\
\hline 9 - Moçambique & $\begin{array}{l}\text { É matéria prima para } \\
\text { a produção da } \\
\text { informação. }\end{array}$ & $\begin{array}{ll}\text { E matéria prima na } \\
\text { produção } & \text { do } \\
\text { conhecimento. } & \end{array}$ & $\begin{array}{l}\text { É } \underset{\text { a }}{ } \text { informação } \\
\text { sistematizada. }\end{array}$ \\
\hline $\begin{array}{l}10 \\
\text { Moçambique }\end{array}$ & Não é informação. & $\begin{array}{ll}\text { É } & \text { dado } \\
\text { sistematizado. }\end{array}$ & $\begin{array}{l}\text { Produto final do processo } \\
\text { de gestão estratégica do } \\
\text { conhecimento. }\end{array}$ \\
\hline $\begin{array}{l}11 \\
\text { Moçambique }\end{array}$ & $\begin{array}{l}\text { É a partir dele que } \\
\text { obtemos informação. }\end{array}$ & $\begin{array}{l}\text { Conjunto de dados } \\
\text { organizados. }\end{array}$ & $\begin{array}{l}\text { Conjunto de informações } \\
\text { que adquirimos ao longo } \\
\text { do tempo. }\end{array}$ \\
\hline 12 - Brasil & 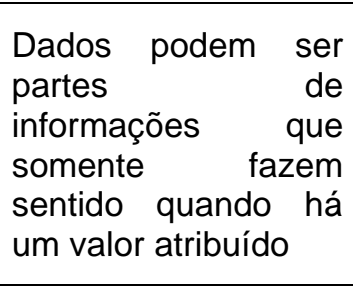 & $\begin{array}{l}\text { A informação é um } \\
\text { tipo de mensagem } \\
\text { que pode ser } \\
\text { transmitida r e } \\
\text { retransmitida por } \\
\text { meio de algum } \\
\text { suporte multimídia. }\end{array}$ & $\begin{array}{l}\text { O conhecimento é a } \\
\text { reunião de diversas } \\
\text { informações sobre } \\
\text { assuntos relacionados ou } \\
\text { não e faz parte das ideias } \\
\text { de um indivíduo. }\end{array}$ \\
\hline 13 - Brasil & $\begin{array}{l}\text { Informação sem } \\
\text { tratamento }\end{array}$ & $\begin{array}{l}\text { Dados tratados e } \\
\text { direcionados }\end{array}$ & $\begin{array}{l}\text { Dados tratados } \\
\text { direcionados e que fazem } \\
\text { algum sentido para alguém }\end{array}$ \\
\hline 14- Brasil & $\begin{array}{l}\text { Dados que devem } \\
\text { ser tratados }\end{array}$ & $\begin{array}{lr}\text { São registros } \\
\text { contextualizados e a } \\
\text { partir dos quais se } \\
\text { podem r fazer } \\
\text { inferências. }\end{array}$ & $\begin{array}{l}\text { É a apropriação das } \\
\text { informações através de } \\
\text { bases de conhecimento } \\
\text { prévias. O conhecimento é } \\
\text { produzido mentalmente (é } \\
\text { implícito) e a partir do } \\
\text { momento que é registrado } \\
\text { se torna novamente } \\
\text { informação (explícita) que } \\
\text { pode ou não gerar novos } \\
\text { conhecimentos } \\
\text { dependendo dos } \\
\text { processos cognitivos de } \\
\text { cada indivíduo. }\end{array}$ \\
\hline 15-Brasil & $\begin{array}{l}\text { Dados } \\
\text { potencialmente } \\
\text { informação. }\end{array}$ & $\begin{array}{lr}\begin{array}{l}\text { Conteúdo } \\
\text { informativo, }\end{array} \\
\text { em ainda } \\
\text { Passível potencial. } \\
\text { interpretação } & \text { de } \\
\text { sistema } & \text { delo } \\
\text { informação, } & \text { mas } \\
\text { ainda não } & \text { sofre } \\
\text { interpretação } & \text { do } \\
\text { usuário } & \text { da } \\
\text { informação. } & \\
\end{array}$ & $\begin{array}{l}\text { Informação } \\
\text { usada quando é } \\
\text { Informação na prática. } \\
\text { interpretada. }\end{array}$ \\
\hline 16-Brasil & $\begin{array}{l}\text { É a representação } \\
\text { bruta da informação, } \\
\text { sem tratamento, sem } \\
\text { organização. }\end{array}$ & $\begin{array}{l}\text { São dados reunidos, } \\
\text { agrupados, formando } \\
\text { um significado. }\end{array}$ & $\begin{array}{l}\text { É a conclusão dos estudos } \\
\text { de dados, ou seja, o que } \\
\text { ficou da informação } \\
\text { processada, } \\
\text { compreensão, } \\
\text { transformação em saber. }\end{array}$ \\
\hline 17 - Brasil & $\begin{array}{l}\text { Dado é um conjunto } \\
\text { de símbolos } \\
\text { "quantificados ou } \\
\text { quantificáveis" } \\
\text { (https://www.ime.usp } \\
\text {.br/ vwsetzer/datagr }\end{array}$ & $\begin{array}{l}\text { Informação é um } \\
\text { conjunto de dados } \\
\text { que computa sentido } \\
\text { a eles }\end{array}$ & $\begin{array}{l}\text { Conhecimento é } \\
\text { informação processada }\end{array}$ \\
\hline
\end{tabular}




\begin{tabular}{|c|c|c|c|}
\hline & ama.html) & & \\
\hline 18- Brasil & $\begin{array}{ll}\text { Dados } & \text { crus, } \\
\text { caracteres sem } \\
\text { contexto definido }\end{array}$ & $\begin{array}{l}\text { Expressão humana } \\
\text { ou matemática, } \\
\text { artes. Dados } \\
\text { contextualizados e } \\
\text { organizados. }\end{array}$ & $\begin{array}{l}\text { Experiência pessoal, junto } \\
\text { de teorias ou não; corpus } \\
\text { histórico. Epistemologias...; } \\
\text { Cultura. }\end{array}$ \\
\hline 19 - Brasil & $\begin{array}{l}\text { Qualquer coisa } \\
\text { passível de análise e } \\
\text { interpretação }\end{array}$ & $\begin{array}{l}\text { Dados analisados e } \\
\text { interpretados }\end{array}$ & $\begin{array}{l}\text { Transformação ocorrida } \\
\text { pela interação com } \\
\text { informação, geralmente } \\
\text { produzindo novos dados } \\
\text { ou informações, durante a } \\
\text { interação, modificando o } \\
\text { estado inicial dos dados. }\end{array}$ \\
\hline 20 - Brasil & $\begin{array}{lr}\text { São } & \text { números, } \\
\text { palavras } & \text { sem } \\
\text { conexão } & \end{array}$ & $\begin{array}{l}\text { São as conexões de } \\
\text { números e palavras }\end{array}$ & $\begin{array}{l}\text { É o todo da informação, } \\
\text { você sabe tal informação e } \\
\text { aí você adquire } \\
\text { conhecimento através da } \\
\text { junção das informações }\end{array}$ \\
\hline 21 - Brasil & $\begin{array}{l}\text { São pequenas } \\
\text { estruturas que se } \\
\text { organizadas podem } \\
\text { se transformar em } \\
\text { informação. }\end{array}$ & $\begin{array}{lr}\text { São } & \text { dados } \\
\text { organizados } & \text { que } \\
\text { possuem relevância } \\
\text { e propósito. }\end{array}$ & $\begin{array}{lr}\text { É algo macro, um conjunto } \\
\text { de } & \text { informações } \\
\text { internalizadas } & \text { pelo } \\
\text { indivíduo. } & \end{array}$ \\
\hline 22 - Brasil & $\begin{array}{l}\text { Dados são conjunto } \\
\text { de informação } \\
\text { referente a um } \\
\text { determinado objeto } \\
\text { ou assunto }\end{array}$ & $\begin{array}{l}\text { Informação é dar a } \\
\text { conhecer um } \\
\text { determinado assunto }\end{array}$ & Conhecimento é sabedoria \\
\hline
\end{tabular}

Fonte: Resultados da pesquisa (2018)

Conforme observa-se no quadro 2 as respostas recebidas, em sua maioria representam apenas a noção que o graduando tem de dado, informação e conhecimento. Tanto no Brasil quanto em Moçambique poucos elaboraram ou tentaram traçar um conceito. Descreveram o dado, informação e conhecimento declarando o que não acham que é cada um deles. Revelam algum entendimento do que é Informação em detrimento do dado, mas há confusões nessa interpretação $O$ conhecimento, por sua vez é identificado, por grande dos estudantes como o conhecimento individual. Pode-se inferir que na mostra não possível perceber a existência de um consenso. O que acompanha o comportamento dos pesquisadores estudados na pesquisa de Zins (2007a)

Assim, buscou-se avaliar quais os principais termos apresentados e apresenta-los de forma sintética. Os termos mais citados nas respostas estão dispostos na figura 2 
Figura 2 - Termos mais citados nas respostas

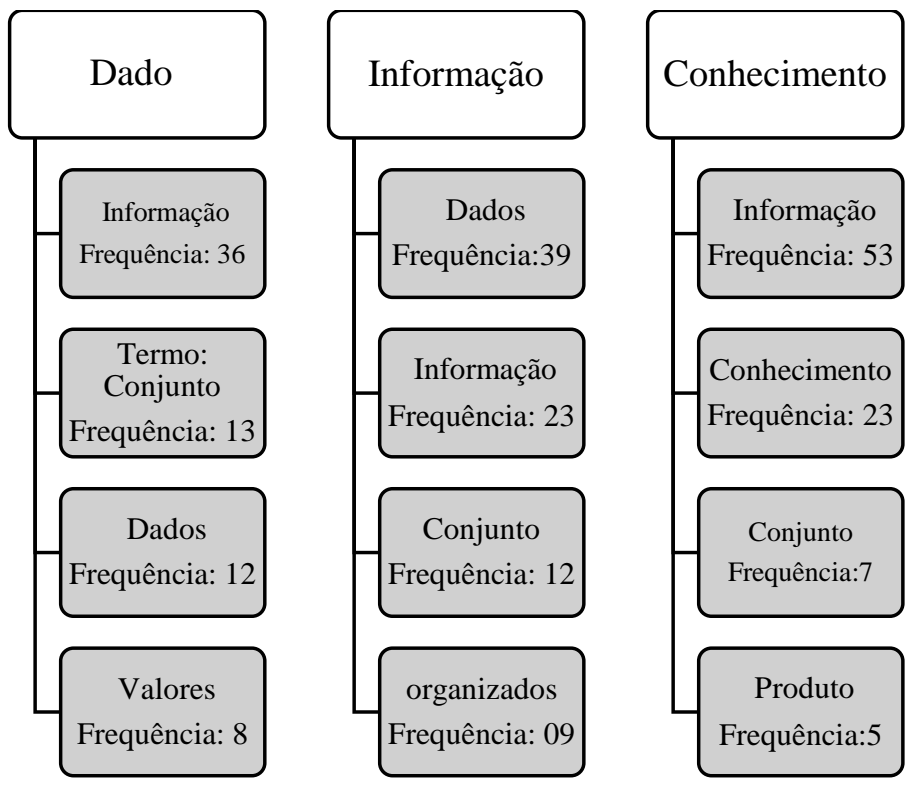

Fonte: Resultados da pesquisa (2018)

É importante verificar que o termo dado (s) aparece com a frequência 12 e de informação 36. Isso parece comprovar o fato do que foi reportado pelos graduandos de que dado não é informação. No entanto na coluna de informação, dado aparece 39 vezes enquanto informação apenas 23 , o que confirma o grau de confusão existente entre os graduandos quanto a esses conceitos. A análise da coluna conhecimento aponta o termo informação com a frequência 53 enquanto conhecimento com apenas 23 . Os graduandos usaram o termo informação para explicar seu entendimento de conhecimento.

No questionário explorou-se também as impressões dos discentes quanto ao conceito de Ciência da Informação e a falta de consenso sobre o termo.

Nas figuras 3 e 4 são representadas as respostas dos graduandos sobre isso. 
Figura 3 - Questão sobre consenso na área

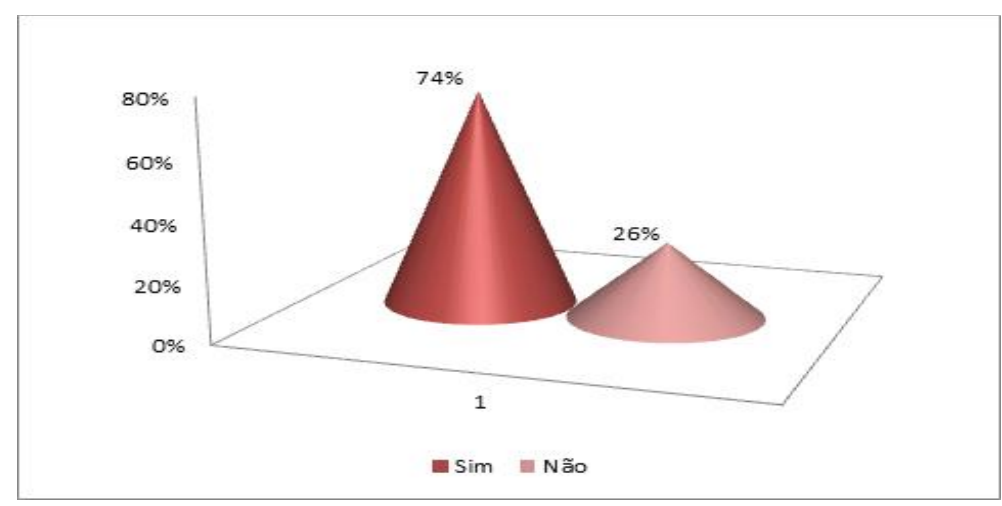

Fonte: Elaborada pelos autores (2018)

A figura 3 mostra as respostas evidenciando a não existência de consenso em relação ao que seja Ciência da informação, visto que $74 \%$ dos pesquisados acreditam que não existe esse consenso

A figura 4, a seguir, mostra a opinião dos discentes sobre a falta de consenso em torno do conceito da área e os prejuízos que podem ocorrer a partir dessa fragilidade.

Figura 4 - falta de consenso e possíveis prejuízos

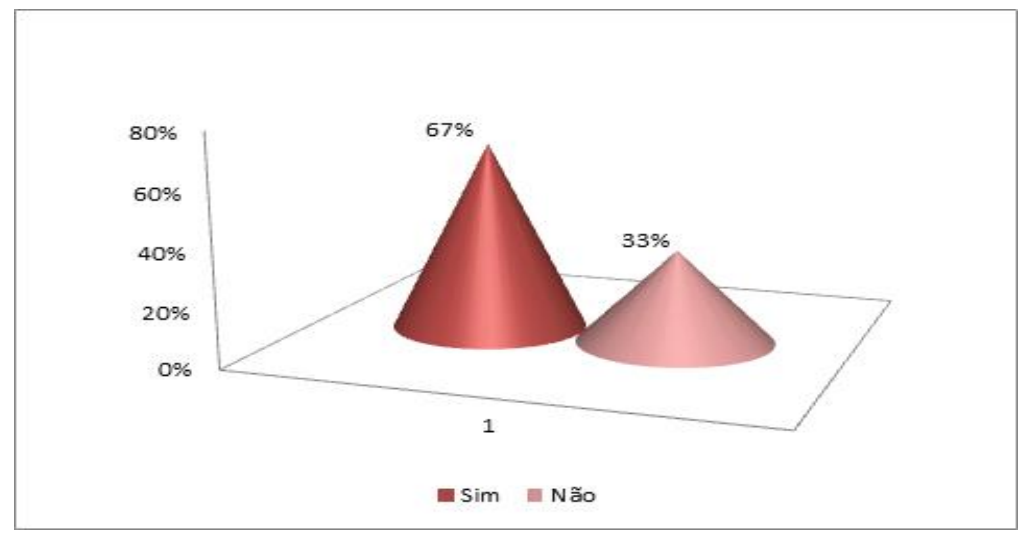

Fonte: Elaborada pelos autores (2018)

Conforme se pode observar no gráfico 5, 67\% dos entrevistados concordam que a falta de consenso na definição de uma área do conhecimento pode prejudicar o desenvolvimento de suas atividades. Torna a área mais frágil e há conflitos que podem ser superados com um consenso. Contudo $33 \%$ do total de graduandos acreditam que falta de consenso não traz prejuízos à área e seus pesquisadores e praticantes. 


\section{CONSIDERAÇÕES FINAIS}

Compreender a organização funcionamento de uma disciplina científica não é tarefa simples e curta. É uma atividade que envolve uma variedade de pesquisas o que demanda tempo e recursos financeiros. Assim, a Ciência da Informação, a Gestão do Conhecimento e a Biblioteconomia enfrentam essa situação quando estão buscando definir os termos Dado, Informação e Conhecimento. Em seus estudos, Zins (2007b) tratou sobre essa discordância, buscando os conceitos de vários especialistas sobre o que acreditam ser dado, informação e conhecimento. Em outro estudo, Zins (2007a) buscou trazer as várias interpretações desses estudiosos acerca da Ciência da Informação.

As respostas mostraram que os alunos não apreenderam corretamente o que é dado, informação e conhecimento. Utilizaram o conceito informação para explicar o que dado e o que conhecimento. Além disso percebeu-se uma certa confusão entre os alunos ao demarcar ou não delinear cada um dos conceitos ou entendimentos. Essas evidências reforçam as ideias de Angeloni, (2003).

As opiniões dos discentes refletem também a falta de consenso na Ciência da Informação, conforme Zins (2007ª̣; 2007b) acerca dos conceitos estudados e também da Ciência da Informação

Importante ressaltar uma limitação quanto à coleta dos dados, o que limitou o número de respondentes que contribuíram para a formação da amostra analisada. A forma de disseminação da coleta tornou-se um empecilho, assim como questões abertas impediram maior participação de discentes.

Sugere-se, então, o desenvolvimento de novas pesquisas que busquem explicar um pouco mais a falta de consenso na área e seus prejuízos.

\section{REFERÊNCIAS}

AHARONY, N. The librarian and the information scientist: different perceptions among Israeli information science students. Library \& Information Science Research, v. 28, n. 2, p. 235-248, 2006. Disponível em: 
http://www.sciencedirect.com/science/article/pii/S0740818806000235. Acesso em: 17 jun. 2018

ANGELONI, M. T. Elementos intervenientes na tomada de decisão. Ciência da informação, Brasilia, v. 32, n. 1, p. 17-22, 2003. Disponível em: http://www.scielo.br/scielo.php?script=sci_abstract\&pid=S0100$19652003000100002 \&$ Ing=en\&nrm=iso\&tlng=pt. Acesso em: 13 jun. 2018.

BORGHOFF, U.; PARESCHI, R. Information technology for knowledge management. Germany: Berlin Springer, 1998.

CAJUEIRO, J. L. G.; SICSU, A. B.; RIBEIRO, A. R. B. Elementos preliminares para a construção de modelos: a contribuição da gestão do conhecimento para instituições de ensino superior. Revista Gestão Industrial, Ponta Grossa, v. 5, n. 3, p. 219-234, 2009.

$\mathrm{CHOO}, \mathrm{C}$. W. The knowing organization: how organizations use information to construct meaning, create knowledge and make decisions. International journal of information management, Nova lorque, v. 16, n. 5, p. 329-340, 1996.

DAVENPORT, A. T.; PRUSAK, L. Ecologia da informação: por que só a tecnologia não basta para o sucesso na era da informação. São Paulo: Futura, 1998(a).

DAVENPORT, A. T.; PRUSAK, L. Conhecimento empresarial: como as organizações gerenciam o seu capital intelectual. Rio de Janeiro: Campus, 1998(b).

DAVID, P. A.; FORAY, D. Economic fundamentals of the knowledge society. Policy Futures in Education, v. 1, n. 1, p. 20-49, 2003. Disponível em: http://journals.sagepub.com/doi/10.2304/pfie.2003.1.1.7. Acesso em: 01 maio 2018.

HUSAIN, S.; NAZIM, M. Concepts of knowledge management among library \& information science professionals. International Journal of Information Dissemination and Technology, v. 3, n. 4, p. 263-269, 2013. Disponível em: http://eprints.rclis.org/31229/. Acesso em: 04 maio 2018.

NONAKA, I.; TAKEUCHI, H. The knowledge-creating company: how japanese companies create the dynamics of innovation. Oxford university press, 1995.

NONAKA, I.; TAKEUCHI, H. Criação de conhecimento na empresa: como as empresas japonesas geram a dinâmica da inovação. 3 ed. Rio de Janeiro: Campus, 1997.

OLIVEIRA, M. (org). Ciência da informação e biblioteconomia: novos conteúdos e espaços de atuação. 2 ed. Belo Horizonte: Editora UFMG, 2011. 
POLANYI, M. The Tacit Dimension. London: Routledge \& Kegan Paul, 1967.

PRODANOV, C. C.; FREITAS, E. C.. Metodologia do trabalho científico: métodos e técnicas da pesquisa e do trabalho acadêmico. 2 ed. Novo Hamburgo: Editora Feevale, 2013.

RAUPP, F. M.; BEUREN, I. M. Como elaborar trabalhos monográficos em contabilidade. Teoria e prática, v. 3, 2006.

RODRIGUES, L. C.; MACCARI, É. A. Gestão do conhecimento em instituições de ensino superior. Revista de Negócios, Blumenau, v. 8, n. 2, 2003.

Disponível em: http://proxy.furb.br/ojs/index.php/rn/article/view/318. Acesso em: 01 mar. 2018.

SARACEVIC, T. Ciência da informação: origem, evolução e relações.

Perspectivas em Ciência da Informação, Belo Horizonte, v. 1, n. 1, 1996.

Disponível em:

http://portaldeperiodicos.eci.ufmg.br/index.php/pci/article/view/235. Acesso em: 18 fev. 2018.

SETZER, V. W. Dado, informação, conhecimento e competência.

DataGramaZero, Rio de Janeiro, n. 0, 1999. Disponível em:

https://brapci.inf.br/index.php/article/view/0000009680. Acesso em: 01 jun.

2020.

SOMASUNDARAM, G.; SHRIVASTAVA, A. Armazenamento e

gerenciamento de informações: como armazenar, gerenciar e proteger informações digitais. [s. I.]: Bookman Editora, 2011.

SVEIBY, K. E. A nova riqueza das organizações: gerenciando e avaliando patrimónios do conhecimento. Rio de Janeiro: Campus, 1998.

TARAPANOFF, K. Inteligência, informação e conhecimento em corporações. Brasília: Instituto Brasileiro de Informação em Ciência e Tecnologia (IBICT), 2006.

WITTGENSTEIN, L. Tractatus Logico-Philosophicus. (Versão em inglês) Estocolmo: Orion, 1962.

ZINS, C. Conceptual approaches for defining 'data', 'information', and 'knowledge'. Journal of the American Society for Information Science and Technology, v. 58, n. 4, p. 479-493, 2007(a). Disponível em: https://onlinelibrary.wiley.com/doi/full/10.1002/asi.20508. Acesso em: 15 jun. 2018.

ZINS, C. Conceptions of Information Science. Journal of the American Society for Information Science and Technology, v. 58, n. 3, p. 335-350, 2007(b). Disponível em: 


\title{
A STUDENT'S LOOK AT THE DISCIPLINES OF THE BIBLIOTECONOMY COURSE ABOUT WHAT ARE DATA, INFORMATION AND KNOWLEDGE
}

\begin{abstract}
Introduction: Every area of knowledge has its terms and concepts that are employed to define a particular occurrence of a specific fact or object. Due to the proximity of information science, knowledge management and librarianship, some terms may have different definitions to describe the same object. Objective: From this perspective, the present study sought to elucidate the following concern: What are the perceptions of the students of the Library Science course about what is data, information and knowledge? Methodology: To obtain an answer to this question, a qualitative research was carried out, which is classified as descriptive, using a bibliographic study on the subjects that guide this theme, as well as applying a survey to Brazilian and Mozambican students. of the Librarianship course. Results: 58 valid answers were obtained and, through the analyses, it was possible to verify that there is no consensus on the definitions provided, since the interviewees believe that the lack of agreement can come to harm the professional and academic development in the area. Conclusion: Taking into account the number of answers, it is concluded that there is a need to harmonize some terms and concepts adopted in in C.I.
\end{abstract}

Descriptors: Data. Information. Knowledge. Librarianship. Information Science.

\section{UNA MIRADA DE LOS ESTUDIANTES DEL CURSO DE BIBLIOTECONOMIA SOBRE LO QUE SON LOS DATOS, LA INFORMACIÓN Y EL CONICIMIENTO.}

\begin{abstract}
RESUMEN
Introducción: Cada área de conocimiento tiene sus términos y conceptos que se emplean para definir una ocurrencia particular de un hecho u objeto específico. Debido a la proximidad de la Ciencia de la Información, la Gestión del Conocimiento y la biblioteconomía, algunos términos pueden tener diferentes definiciones para describir el mismo objeto. Objetivo: desde esta perspectiva, el objetivo el presente estudio buscó dilucidar la siguiente preocupación: ¿Cuáles son las percepciones de los alumnos del curso de las Ciencias de la Biblioteconomi sobre lo que son los Datos, la Información y el Conocimiento? Metodología: Para obtener una respuesta a esta pregunta, se realizó una investigación cualitativa, que se clasifica como descriptiva, em la que se utilizó un estudio bibliográfico sobre las aasignaturas que guían este tema, así como la aplicación de una encuesta a los estudiantes brasileños y mozambiqueños. del curso de Biblioteconomía. Resultados: 58 respuestas válidas se obtuvieron y, a través de los análisis, fue posible verificar que no hay consenso sobre las definiciones proporcionadas, ya que los entrevistados creen que la falta de acuerdo puede perjudicar el desarrollo profesional y académico en el área. Conclusión:
\end{abstract}

Inf. Inf., Londrina, v. 25, n. 2, p. 484 - 508, abr./jun. 2020. 
Teniendo en cuenta el número de respuestas, se concluye que es necesario llevar a cabo uma armonización entre algunos términos y conceptos adoptados en la C.I.

Descriptores: Datos. Información. Conocimiento Biblioteconomía. Ciencias de la información.

Recebido em: 02.09.2019

Aceito em: 19.04 .2020 